\title{
Studies on the dynamics the valve train with machined valve springs
}

An analysis of the literature for currently used solutions of valve trains in internal combustion engines and analytical studies on the dynamics the valve train of the internal combustion engine provided with machined valve springs were carried out. The aim of the study was to compare the dynamic parameters of the two valve trains for the established internal combustion engine: the first one equipped with machined springs and the second one with coil springs. The numerical models for investigated valve trains, using the Finite Element Method and additional mathematical relationships were developed and presented in the article. The article describes the results of the researches and formulated conclusions.

Key words: dynamics, valve train, combustion engine, machined spring, finite element method

\section{Introduction}

The valve train is a very important subsystem in the combustion engine treated as the system for change of the chemical energy of combustion into mechanical one. Its design has varied with time becoming more complex due number of valves per cylinder, number of cams per valve, number of valve springs etc. There was observed tendency for downsizing and use of lightweight parts as valvetrain components. The control of mechanical valve trains sometimes includes electric motor or hydraulic units driving phasers used to change valve timing. The stiffness, dimensions and mass of valve springs are critical for operation of mechanical and some advanced types of valve trains, i.e. electromechanic or electromagnetic one. The one aim of the present study is to investigate the dynamical parameters of machined valve springs with some geometrical parameters like these of classical coil valve springs.

During studies were investigated components the valve train from the combustion engine used i.e. for tribological studies [1]. The scheme of such valve train is shown in the Figure 1. Inlet valves operate under fully variable control.

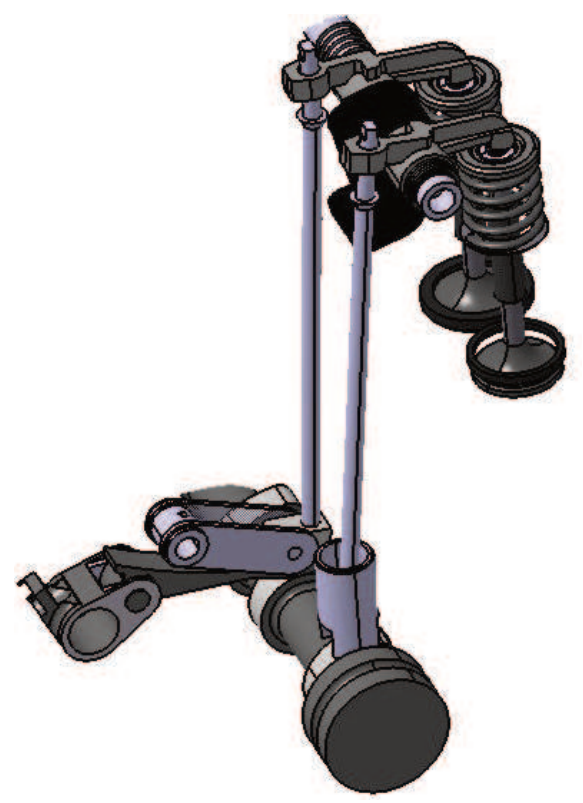

Fig. 1. The scheme of valve train from the engine for tribological studies
The two models of the chosen valve train but with different valve springs were elaborated using the Finite Element Method. Dynamical parameters obtained for the valve train with machined valve springs were compared with those for valve train with classical coil springs.

\section{Types of valvetrain}

The pushrod valve train systems can be used not only in both SI or CI four-stroke combustion engines with classical valve timing and combustion process, but also in similar engines with:

- modified combustion process by varying valve timing via the phasor [2-10],

- modified combustion process by varying valve timing via other methods [11-13],

- modified combustion process by varying valve lifts via different cams [14-32],

- modified combustion process by continuously varying valve lifts [33-34],

- modified combustion process and the pneumatic energy accumulator [35].

There are five most often met types of valve train system with poppet valves.

- The Direct Acting OHC Valve Train (Fig. 2a), also known as the Bucket Style Follower OHC. It is used in i.e. Ford Ztec, Olds Quad 4. This type has: high rigidity during functioning which enable to be used at high engine speeds, high friction because of contact between cam lobe and tappet surface, high values of inertial masses [36].

- The End Pivot Rocker Arm OHC Valve Train (Fig. 2b), also known as the Finger Type Follower OHC. It is used in i.e. Ford Modular, Pinto and Ranger 4 Cyl., Mitsubishi 4G63, GM Ecotec, Chrysler 2.2L. This type has: low friction because of rolling contact between cam and rocker arm, high friction for sliding contact, high sensitivity at rocker arm oscillation, small values of acceleration due to cam concavity which doesn't permit to be used at high engine speeds, small cam profile due to rocker ratio [36].

- The Centre Pivot Rocker Arm OHV Valve Train (Fig. 2c), used in i.e. Honda B18, Porsche. It is characterized by low friction for rolling contact between cam and 
rocker, high sensitivity at rocker oscillation, low stiffness as a function of rocker ratio [36].

- The Centre Pivot Cam Follower OHV Valve Train (Fig. 2d) which has similar characteristics with the third type [36]. It is used in Ford Escort CVH.

- The Pushrod OHV Valve Train (Fig. 2e). This type is very flexible because of the length of the pushrod and can't be use at high engine speeds [36]. It is used in the GM 556-hp 6.2L LSA V8 OHV engine of the Cadillac CTS-V.

The friction due to valve train system represent $7.5-21 \%$ of total engine friction loss [36].

The variation of the first type is the Double OverHead Cam (DOHC) Valve train, sometimes called "Twin Cam" or "Double Cam", used in most modern cars.

A DOHC engine has usually two camshafts and 4 valves per cylinder. There exists also the configuration with five valves per cylinder. One camshaft operates intake valves installed on one side, while another camshaft controls outlet valves on the opposite side. Camshafts can be installed further apart from each other. This allows the inlet valves to be at a larger angle from the outlet valves, which results in a more direct air flow through the engine with less obstruction. A DOHC engine produces more power out of smaller engine volume. It is used in i.e. 3.5-liter V6 DOHC engine of the 2003 Nissan Pathfinder.

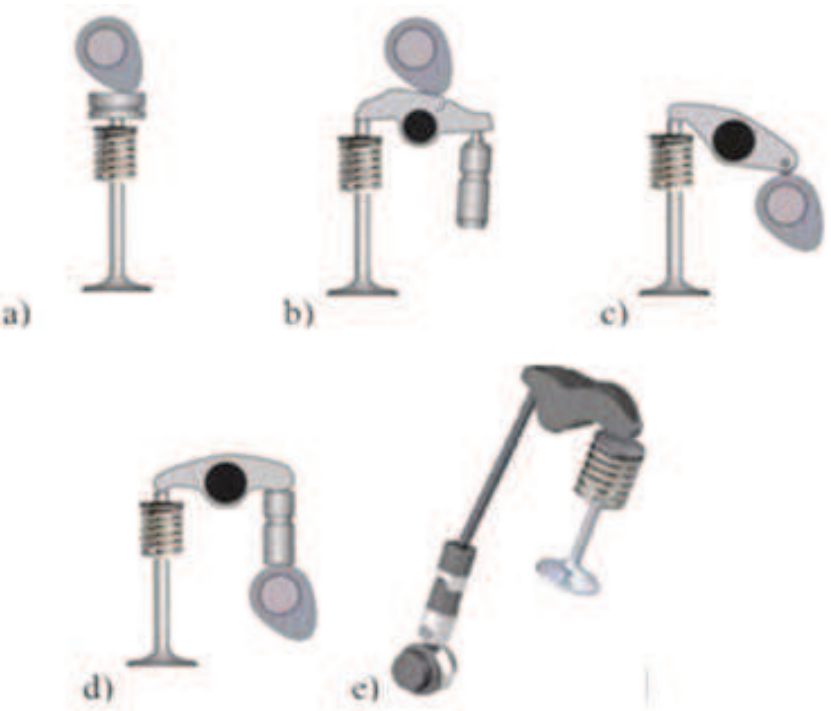

Fig. 2. Types of Valve Train: a) Direct Acting OHC, b) End Pivot Rocker Arm OHC, c) Centre Pivot Rocker Arm OHV, d) Centre Pivot Cam Follower OHV, e) Pushrod OHV [36]

\section{Classical types of valve springs}

The functions of valve springs are presented in [37].

Some typical winding shapes of coil springs are shown in [38]. Helical coil springs with different winding shapes are usually used [39].

Some typical cross-sections of a valve spring wire are shown in [38]. Elliptical cross-sections allow a reduction of the overall height. Multi-arc profiles (MA) are generated from several circular segments with differing radii and center points. Compared to elliptical cross sections, MA profiles has better stress distribution and allow better utilization of the material.
According to [40], the use of MA profiles in combination with beehive winding reduces the spring forces in a valve train by $13 \%$. According to [37], the valve closing load is conveyed axially along the spring, which stresses the material principally in torsion. For the valve, open and the valve closed conditions, the ratio of spring loads is usually in the region of $2: 1$.

Spring end coils are ground flat and square with the spring axis and are also diametrically opposed, to minimize an inherent tendency towards bowing of the spring during its compression.

According to [38], nearly without exception valve springs of current engines have a progressive behavior. This behavior is mainly caused by a non-constant pitch between adjacent coils. The coils with a lower pitch come into contact earlier than coils with a higher pitch. The active part of the spring is reduced resulting in increasing total spring stiffness with increasing compression of the spring. The characteristic becomes progressive and resonant frequencies increases.

According to [37], if the frequency of load coincides with the natural vibration frequency of the valve spring itself, a phenomenon known as spring 'surge' may develop because of resonance effects. According to [41], springs with asymmetric shapes are less prone to surging because of lower moving masses and geometrical reasons.

According to [38] the further reduction of the moving mass can be obtained using conical valve springs. The smaller spring fixings and collars are possible, and the solid length is marginally shorter. They have the less progressive characteristics than the cylindrical springs.

Beehive springs are a combination of cylindrical and conical springs. The moving mass is reduced by the conical part and the cylindrical part provide progressive characteristic.

The methods to reduce valve spring surging are presented in [37]. According to [42], the pneumatic valve springs are used, for example, in high-speed Formula One racing engines. Pneumatic valve springs enable high rotational speeds of up to $20000 \mathrm{rpm}$ due to their progressive characteristic and the reduced number of moving parts.

According to [43], the stock valve springs can operate to about 5,500 to $6,000 \mathrm{rpm}$, but beyond that it is needed stiffer springs, double springs or even triple springs depending on the engine design. The design, materials and methods of manufacturing for valve springs are presented in [37]. The failure modes of valve springs, especially fatigue, are presented in [44-46].

\section{Machined valve springs}

The pushrod valve train systems can be used with classical valve springs replaced with machined valve springs, which strategy is used in the other devices [47]. The machined springs can possess the same free length, mean diameter and thickness equal to the diameter of the wire. This allows for the use of some original components like valves, keys, spring retainers in the valve train.

One example of use the machined spring was reported in [48], where was presented a displacer spring and displacer/spring assembly for use in a free-piston Stirling engines (FPSE). The machined spring provided enhanced structural 
accuracy which, in turn, leads to the elimination of lateral and side loads as compared to prior art wire-wound helical springs.

The analysis was carried out for machined springs with parameters like those for coil valve springs. Each valve in the analyzed valve train mated with the set of two springs: the outer and the inner. The free height for those springs was of $40.86 \mathrm{~mm}$. For outer spring the outer diameter was equal $27.5 \mathrm{~mm}$, the wall thickness was of $3.75 \mathrm{~mm}$. For the inner spring, the outer diameter was of $20 \mathrm{~mm}$ and the thickness was of $2.6 \mathrm{~mm}$. The spring rate of the original coil spring set was equal $55 \mathrm{~N} / \mathrm{mm}$, so such rate of machined spring set should be close to that value. The geometry of machined springs was shown in the Figure 3.

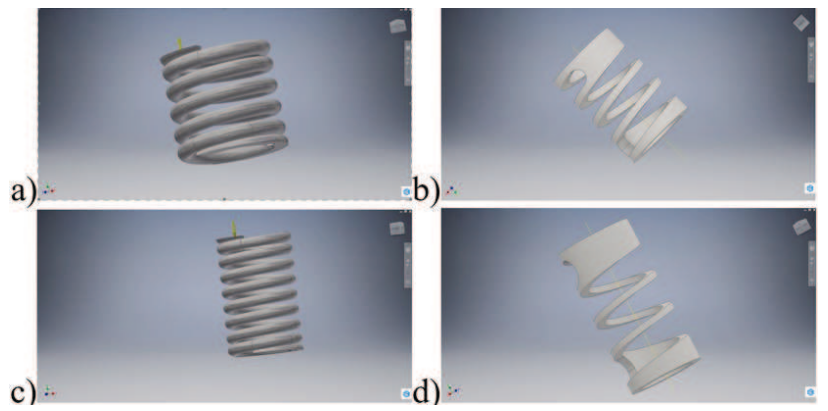

Fig. 3. Coil springs: a) outer, c) inner and machined springs: b) outer, d) inner used in the analyzed valve train

\section{The model of analyzed valve train}

The model of analyzed valve train consists of two drives: the first for inlet valve and the second for outlet one. Model was elaborated with FEM. The geometrical parameters were as in the original configuration. The valve stroke was of $9 \mathrm{~mm}$. The analysis was carried out with the constant rotation speed of the camshaft and for two variants: the first with coil springs and the second with machined springs. Except springs, each component was modelled using stiff finite elements connected to the other components by the elastic-damping joints or contact elements. The friction coefficient in the contact between sliding surfaces was assumed to be constant and equal 0.1 and between rolling surfaces to be constant and equal 0.03 . The material of stiff elements was assumed to be steel with the equivalent: Young modulus $\mathrm{E}=210000 \mathrm{MPa}$, Poisson ration $v=$ 0.3 and density $\rho=7,800 \mathrm{~kg} / \mathrm{m}^{3}$.

It was assumed, that the stiffness between cam and the follower is the sum of the stiffness $\mathrm{k}_{\mathrm{r}-\mathrm{c}}$ in contact between roller and cam and the stiffness $\mathrm{k}_{\mathrm{r}-\mathrm{f}}$ in contact between roller and the follower. The stiffness in contact between pushrod and follower was equal to half the pushrod stiffness $\mathrm{k}_{\text {pushrod. }}$. The stiffness in the contact between pushrod and rocker arm was the sum of half the pushrod stiffness $\mathrm{k}_{\text {pushrod }}$ and the stiffness $\mathrm{k}_{\text {raps }}$ of part the rocker arm on the pushrod side. The stiffness between the rocker arm and valve was the sum of the stiffness $k_{\text {ravs }}$ of part the rocker arm on the valve side and half the valve stiffness $k_{\text {valve }}$. The stiffness between the rocker arm and the axis was equal to the axis stiffness $\mathrm{k}_{\text {axis }}$. The stiffness between valve and its insert was equal to half the valve stiffness $k_{\text {valve }}$. The damping coefficient values in each contact zone was assumed to be the same and equal $5 \mathrm{Ns} / \mathrm{m}$.
To estimate the stiffness $\mathrm{k}_{\mathrm{r}-\mathrm{c}}$ in the contact between roller and the cam, the FEM sub-models of the camshaft were elaborated and presented in the Figures 4 - for the inlet valve and in the Figure 5 - for the outlet one. The camshaft was loaded by the force $F$ with linearly raised values up to $1,000 \mathrm{~N}$. The camshaft was fixed on the cylindrical surfaces 1 and 2 . For the given $i$-th value of the force $F(i)$, the displacement $d_{r-c}(i)$ of the middle point on the cam surface was computed. Then the stiffness $\mathrm{k}_{\mathrm{r}-\mathrm{c}}$ for the step number $\mathrm{i}$ of the analysis was estimated as the ratio of such force value $\mathrm{F}(\mathrm{i})$ and displacement $\mathrm{d}_{\mathrm{r}-\mathrm{c}}(\mathrm{i})$.

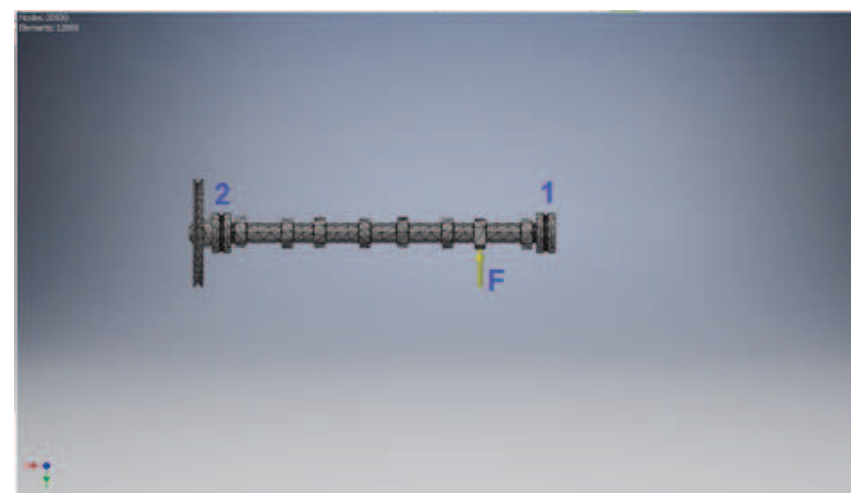

Fig. 4. The grid of finite elements for the sub-model of the camshaft loaded by the force $F$, for the case of inlet valve

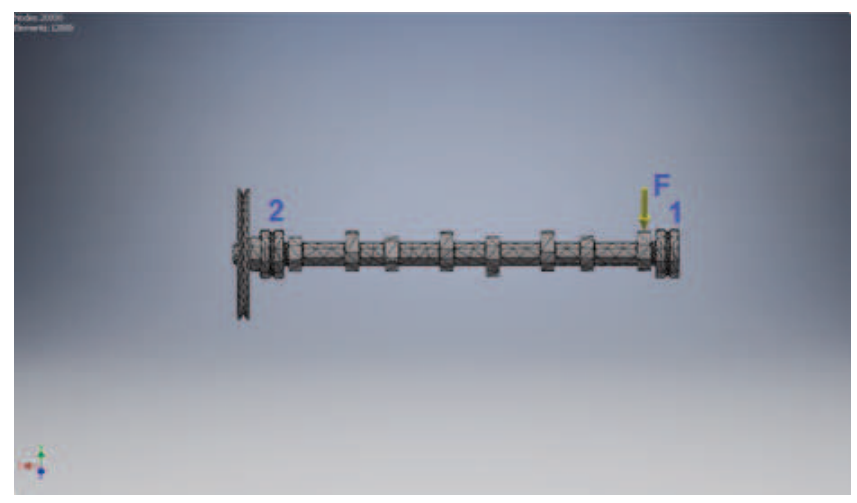

Fig. 5. The grid of finite elements for the sub-model of the camshaft loaded by the force $F$, for the case of outlet valve

To estimate the stiffness $\mathrm{k}_{\mathrm{r}-\mathrm{f}}$ in the contact between roller and the follower, the FEM sub-model of the follower was elaborated and shown in the Figures 6. The follower was loaded by the force $\mathrm{F}$ with linearly raised values up to 1,000 $\mathrm{N}$ and uniformly distributed along the roller axis. The follower was fixed on the inner spherical surface 1 mating with the pushrod. For the given i-th value of the force F(i), the displacement $d_{r-f}(i)$ of the middle point on the roller axis surface was calculated. Then the stiffness $k_{r-f}$ for the step number $i$ of the analysis was estimated as the ratio of such force value $F(i)$ and displacement $d_{r-f}(i)$.

As mentioned earlier, assumed stiffness values in the contact between pushrod and the follower and in the contact between pushrod and rocker arm were the same. To estimate the stiffness in such contacts, the FEM sub-model of the pushrod was elaborated and presented in the Figure 7. The pushrod was loaded by the force $\mathrm{F}$ with linearly raised values up to $1,000 \mathrm{~N}$. The pushrod was fixed on the outer 
spherical surface 1 mating with the rocker arm screw. For the given $i$-th value of the force $F(i)$, the displacement $d_{\text {push- }}$ rod(i) of the middle point on the inner pushrod surface was obtained. Then the stiffness $\mathrm{k}_{\text {pushrod }}$ for the step number $\mathrm{i}$ of the analysis was estimated as the ratio of such force value $\mathrm{F}(\mathrm{i})$ and displacement $\mathrm{d}_{\text {pushrod }}(\mathrm{i})$. The stiffness values in the contact between pushrod and the follower and in the contact between pushrod and rocker arm were equal the half of obtained stiffness $\mathrm{k}_{\text {pushrod. }}$

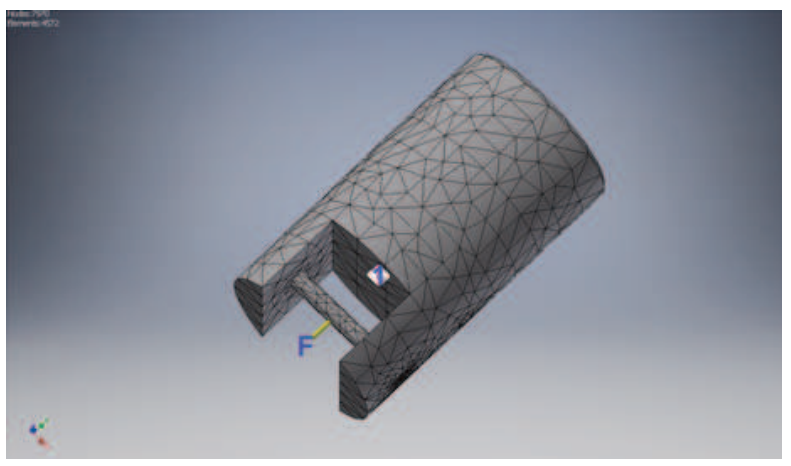

Fig. 6. The grid of finite elements for the sub-model of the follower loaded by the force $F$

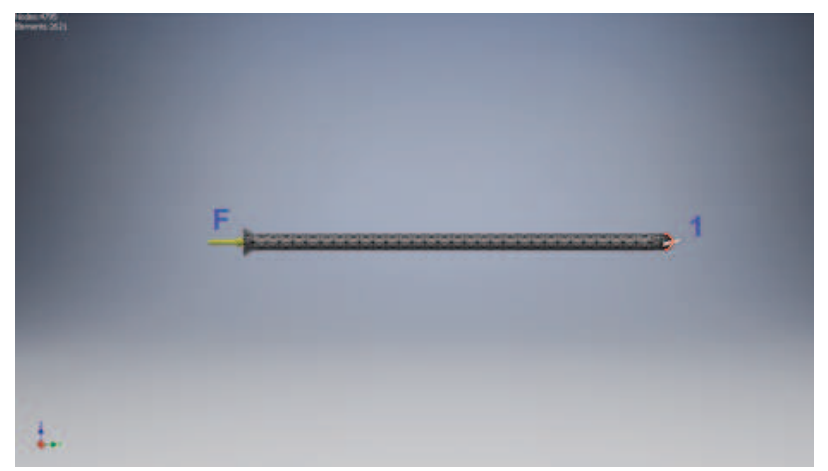

Fig. 7. The grid of finite elements for the sub-model of the pushrod loaded by the force $\mathrm{F}$

To estimate the stiffness $k_{\text {raps }}$ of the rocker arm on the pushrod side, the FEM sub-model of the rocker arm was elaborated and presented in the Figure 8. The rocker arm was loaded by the force $\mathrm{F}$ with increasing values up to 1000 $\mathrm{N}$ and acting along the axis of the rocker arm screw. The rocker arm was fixed on the semicylindrical surface 1 and on the axis the bearing surface 2. For the given i-th value of the force $F(i)$ the displacement $d_{\text {raps }}(i)$ of the loaded point the rocker arm was calculated. Then the stiffness $k_{\text {raps }}$ for the step number $\mathrm{i}$ of the analysis was estimated as the ratio of such force value $\mathrm{F}(\mathrm{i})$ and displacement $\mathrm{d}_{\text {raps }}(\mathrm{i})$.

To estimate the stiffness $\mathrm{k}_{\text {ravs }}$ of the rocker arm on the valve side, the FEM sub-model of the rocker arm was elaborated and shown in the Figure 9. The rocker arm was loaded by the force $\mathrm{F}$ with linearly raised values up to $1,000 \mathrm{~N}$ and acting along the axis of the valve. The rocker arm was fixed on the inner cylindrical surface the screw hole 1 and on the axis the bearing surface 2 . For the given i-th value of the force $F(i)$, the displacement $d_{\text {ravs }}(i)$ of the loaded point the rocker arm was computed. Then the stiffness $k_{\text {ravs }}$ for the step number $i$ of the analysis was estimated as the ratio of such force value $\mathrm{F}(\mathrm{i})$ and displacement $\mathrm{d}_{\text {ravs }}(\mathrm{i})$.

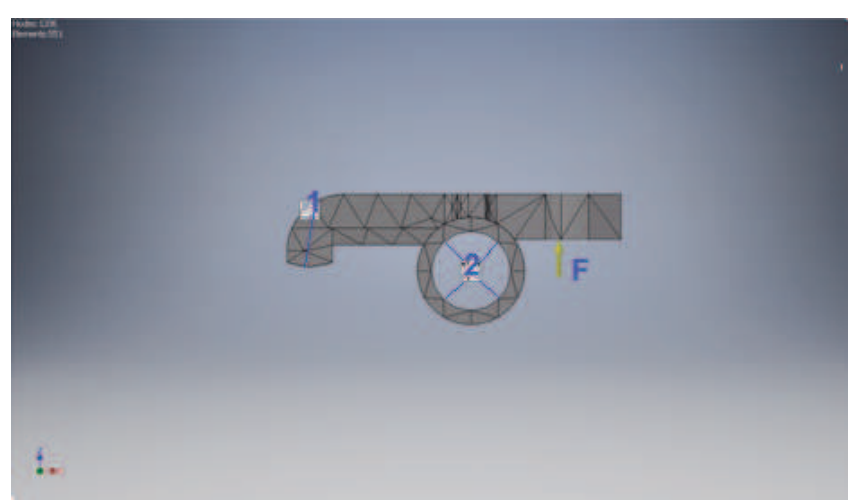

Fig. 8. The grid of finite elements for the sub-model of the rocker arm loaded by the force $F$ on the pushrod side

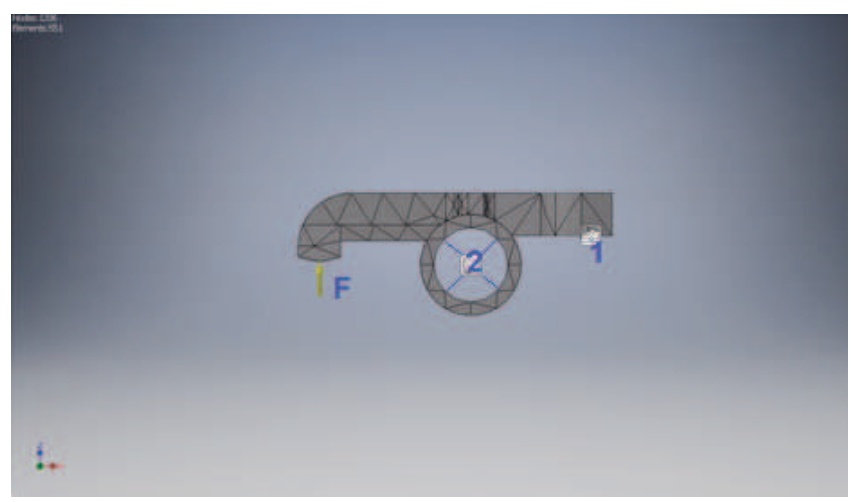

Fig. 9. The grid of finite elements for the sub-model of the rocker arm loaded by the force $\mathrm{F}$ on the valve side

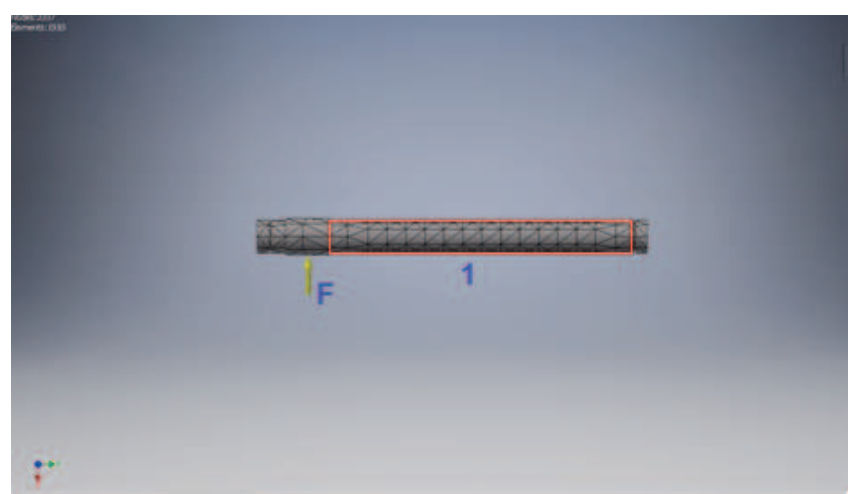

Fig. 10. The grid of finite elements for the sub-model of the rocker arm axis loaded by the force $\mathrm{F}$ for the outlet valve case

To estimate the stiffness $\mathrm{k}_{\mathrm{axis}}$ of the rocker arm axis, the FEM sub-models of the rocker arm axis were prepared and shown in the Figure 10 for the inlet valve and in the Figure 11 for the outlet one. The rocker arm was loaded by the force $\mathrm{F}$ with linearly raised values up to $1,000 \mathrm{~N}$ and uniformly distributed along the axis of rocker arm bearing. For the outlet valve, the rocker arm was fixed on the cylindrical surface 1. For the inlet valve, the rocker arm axis was fixed on the cylindrical surfaces 1 and 2 . For the given $i$-th value of the force $\mathrm{F}(\mathrm{i})$, the displacement $\mathrm{d}_{\mathrm{axis}}(\mathrm{i})$ of the loaded point the rocker arm was obtained. Then the stiffness $k_{\text {axis }}$ for the step number $i$ of the analysis was estimated as the ratio of such force value $F(i)$ and displacement $d_{\text {axis }}(i)$.

To estimate the stiffness $k_{\text {valve }}$ of the valve, the FEM sub-model of the valve were prepared and shown in the 
Figure 12. The valve was loaded by the spring force $\mathrm{S}$ with linearly raised values up to $400 \mathrm{~N}$ and by the pressure from the gas in cylinder with values up to $7 \mathrm{MPa}$. The valve was fixed on the conical seat surface 1 . For the given i-th value of the force $\mathrm{S}(\mathrm{i})$ and gas pressure $\mathrm{p}$, the displacement $d_{\text {valve }}(i)$ of the valve tip was computed. Then the stiffness $\mathrm{k}_{\mathrm{valve}}$ for the step number $\mathrm{i}$ of the analysis was estimated as the ratio of such force value $F(i)$ and displacement $d_{\text {valve }}(i)$.

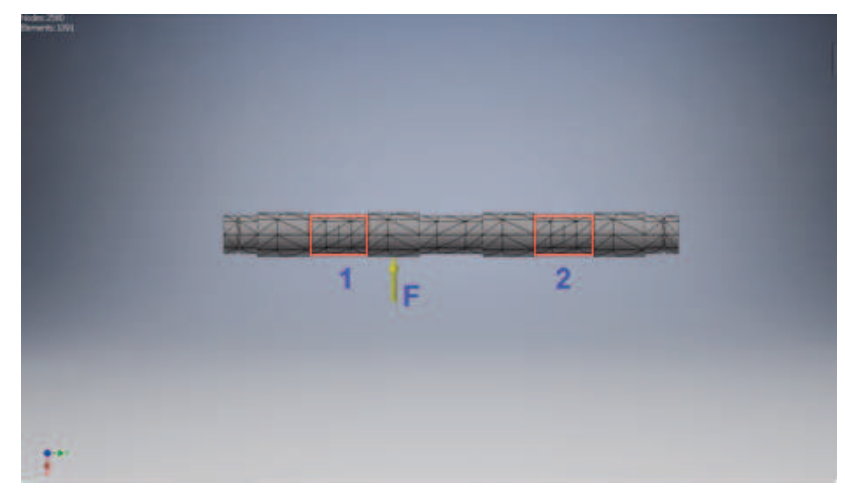

Fig. 11. The grid of finite elements for the sub-model of the rocker arm axis loaded by the force $\mathrm{F}$ for the inlet valve case

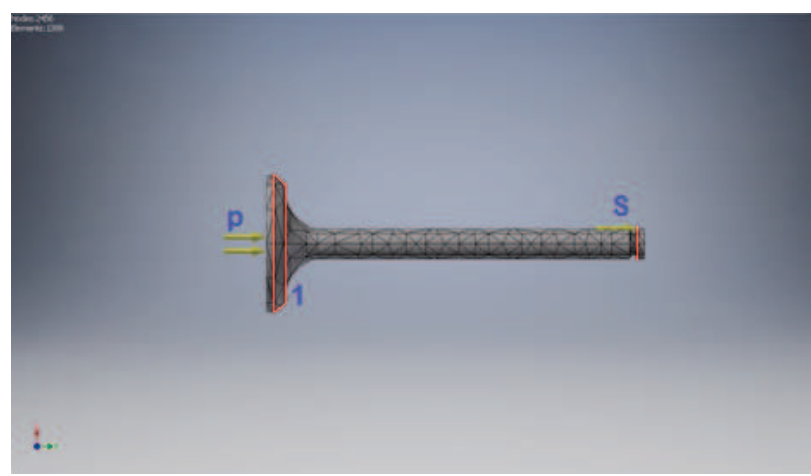

Fig. 12. The grid of finite elements for the sub-model of the valve loaded by the spring force $\mathrm{S}$ and gas pressure $\mathrm{p}$

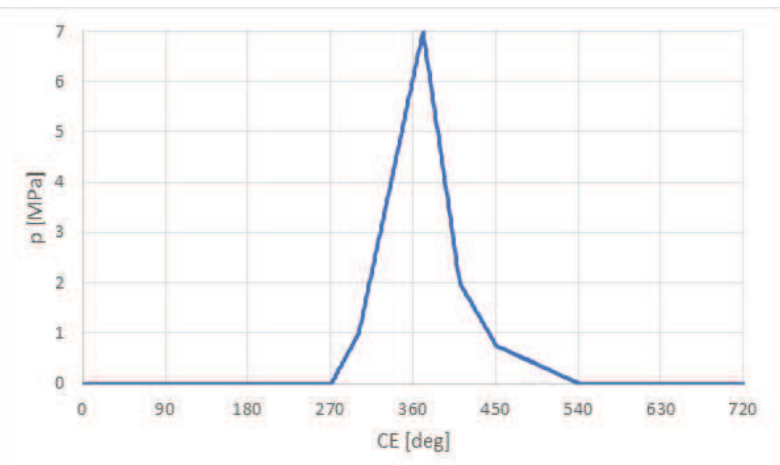

Fig. 13. The modelled course of gas cylinder pressure $p$ against crankshaft rotation angle $\mathrm{CE}$

The modelled course of gas pressure $p$ against the crankshaft rotation angle CE was shown in the Figure 13.

The coil springs was modelled using joints with values of the stiffness and the damping coefficients equivalent to those of real valve springs. The machined springs were also modeled using FEM, but with the elastic solid finite elements. The grid of finite elements for the machined springs was shown in the Figure 14. a)

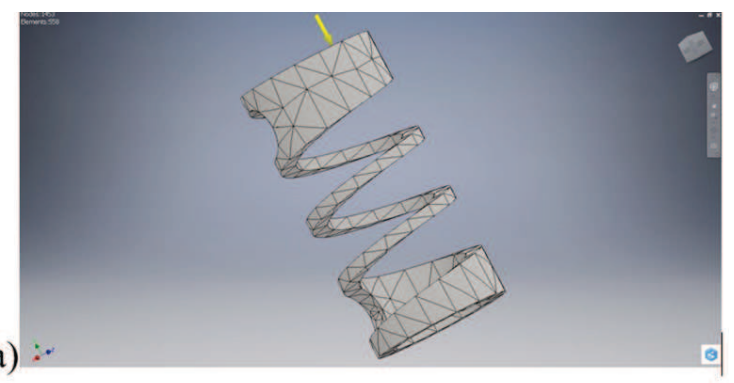

b)

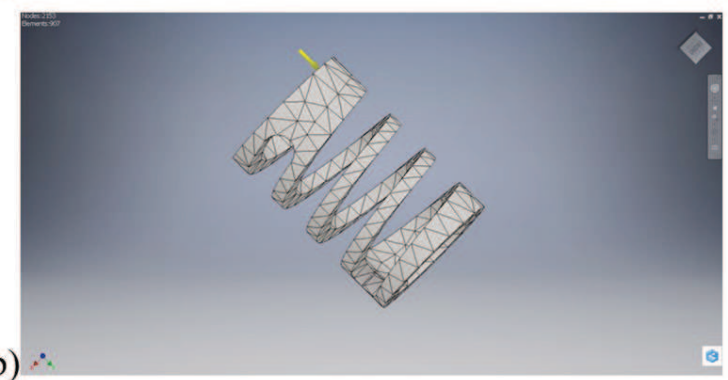

Fig. 14. The grid of finite elements for machined springs a) large and b) small applied in the model of the analyzed valve train

One of the spring front surface was fixed and the force $\mathrm{F}$ was applied to the opposite front surface. The force was evenly distributed over the circumference the spring front surface. The value of the force was constant for the each case of analysis, but varied up to reaching the spring deflection equal $12 \mathrm{~mm}$. The distributions of displacements and von Misses stresses were recorded for each case of analysis.

Also, the modal analysis was provided for machined springs. One of the spring front surface was fixed and the spring was preloaded by the initial displacement of $6 \mathrm{~mm}$ along the spring axis. It was calculated the modal frequency values and equivalent modes of spring deformations.

\section{Results}

The resulted values of displacement $d_{r-c}$ of points the camshaft sub-model loaded by the force $\mathrm{F}=1,000 \mathrm{~N}$ was presented in the Figure 15, for the inlet valve and in the Figure 16, for the outlet one. The corresponding estimated stiffness $\mathrm{k}_{\mathrm{r}-\mathrm{c}}$ value was equal $37,000 \mathrm{~N} / \mathrm{mm}$ for inlet valve and $2,380,000 \mathrm{~N} / \mathrm{mm}$ for the outlet one.

The calculated values of displacement $\mathrm{d}_{\mathrm{r}-\mathrm{f}}$ of points the follower sub-model loaded by the force $\mathrm{F}=1,000 \mathrm{~N}$ was presented in the Figure 17. The corresponding estimated stiffness $\mathrm{k}_{\mathrm{r}-\mathrm{f}}$ value was of $26,000 \mathrm{~N} / \mathrm{mm}$.

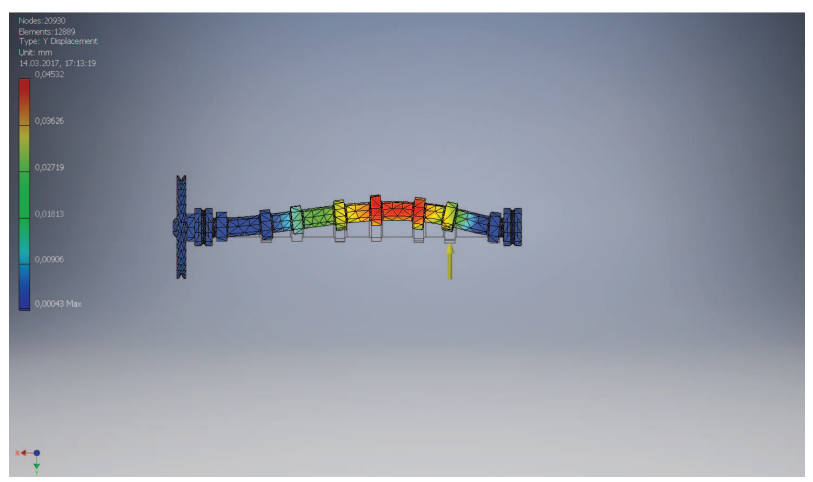

Fig. 15. The displacements of points the camshaft sub-model loaded by the force $\mathrm{F}=1,000 \mathrm{~N}$, for the case of inlet valve 


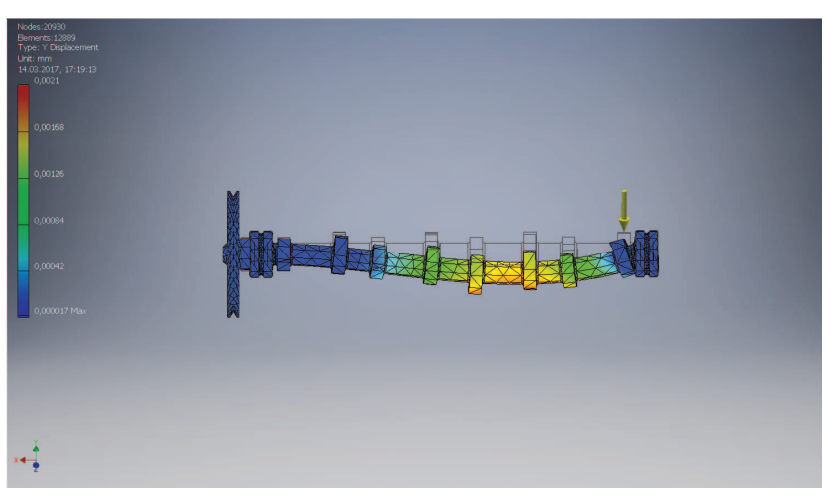

Fig. 16. The displacements of points the camshaft sub-model loaded by the force $\mathrm{F}=1,000 \mathrm{~N}$, for the case of outlet valve

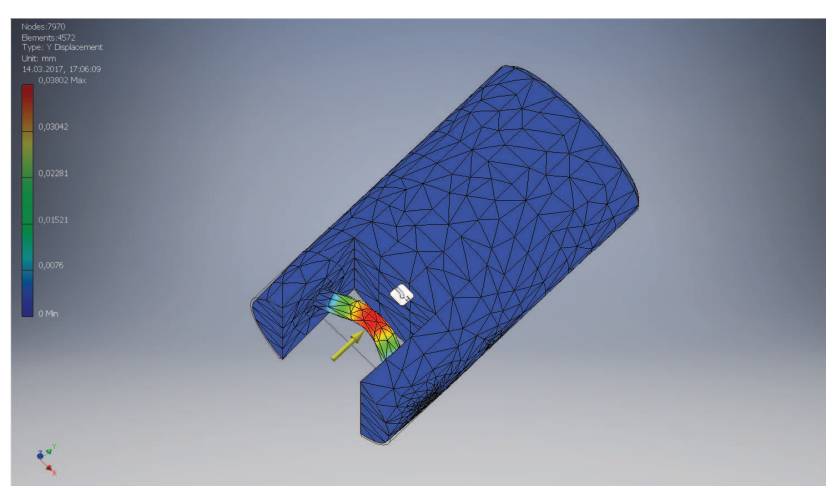

Fig. 17. The displacements of points of the follower sub-model loaded by the force $\mathrm{F}=1,000 \mathrm{~N}$

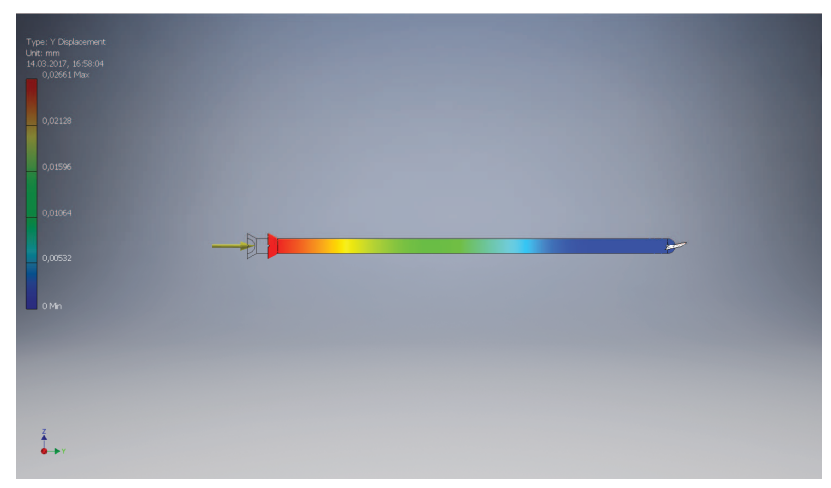

Fig. 18. The displacements of points the pushrod sub-model loaded by the force $\mathrm{F}=1,000 \mathrm{~N}$

The resulted values of displacement $d_{\text {pushrod }}$ of points the pushrod sub-model loaded by the force $\mathrm{F}=1,000 \mathrm{~N}$ was presented in the Figure 18. The corresponding estimated stiffness $\mathrm{k}_{\text {pushrod }}$ value was equal $38,000 \mathrm{~N} / \mathrm{mm}$.

The calculated values of displacement $d_{\text {raps }}$ of points the rocker arm sub-model loaded by the force $\mathrm{F}=1000 \mathrm{~N}$ on the pushrod side was shown in the Figure 19. The estimated stiffness $\mathrm{k}_{\text {raps }}$ value was of $189,000 \mathrm{~N} / \mathrm{mm}$.

The resulted values of displacement $d_{\text {ravs }}$ of points the rocker arm sub-model loaded by the force $\mathrm{F}=1,000 \mathrm{~N}$ on the valve side was presented in the Figure 20. The estimated stiffness $k_{\text {ravs }}$ value was equal 100,000 N/mm.

The calculated values of displacement $d_{\text {axis }}$ of points the sub-model of the rocker arm axis loaded by the force $\mathrm{F}=$ $1,000 \mathrm{~N}$ was shown in the Figure 21 for the outlet valve and in the Figure 22 for the inlet one. The estimated stiffness $\mathrm{k}_{\mathrm{axis}}$ value was equal $1,520,000 \mathrm{~N} / \mathrm{mm}$ for the outlet valve and $1,250,000 \mathrm{~N} / \mathrm{mm}$ for the inlet one.

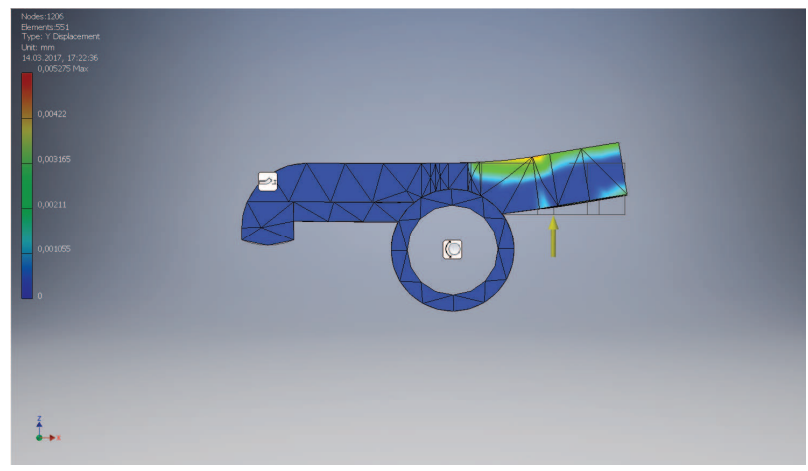

Fig. 19. The displacements of points the rocker arm sub-model loaded by the force $\mathrm{F}=1000 \mathrm{~N}$ on the pushrod side

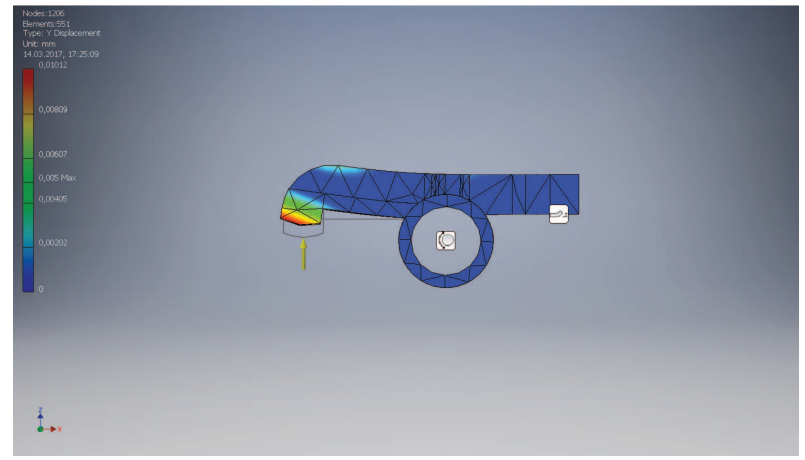

Fig. 20. The displacements of points of the rocker arm sub-model loaded by the force $\mathrm{F}=1000 \mathrm{~N}$ on the valve side

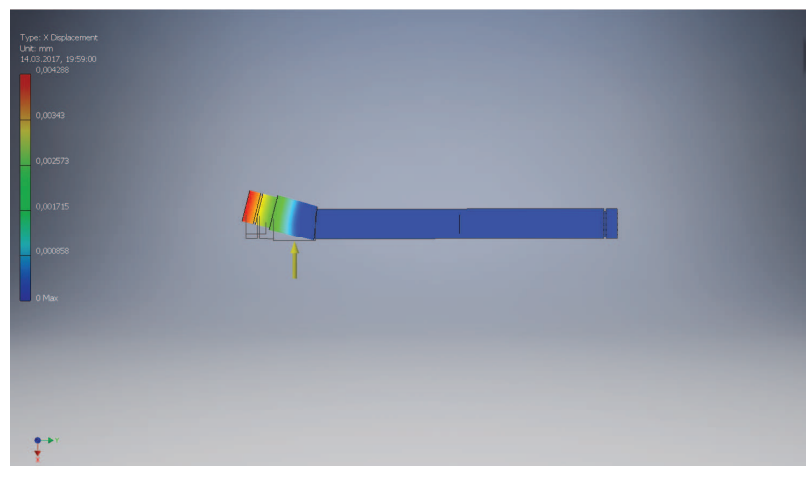

Fig. 21. The displacements of points the sub-model of the rocker arm axis loaded by the force $\mathrm{F}=1000 \mathrm{~N}$ for the outlet valve

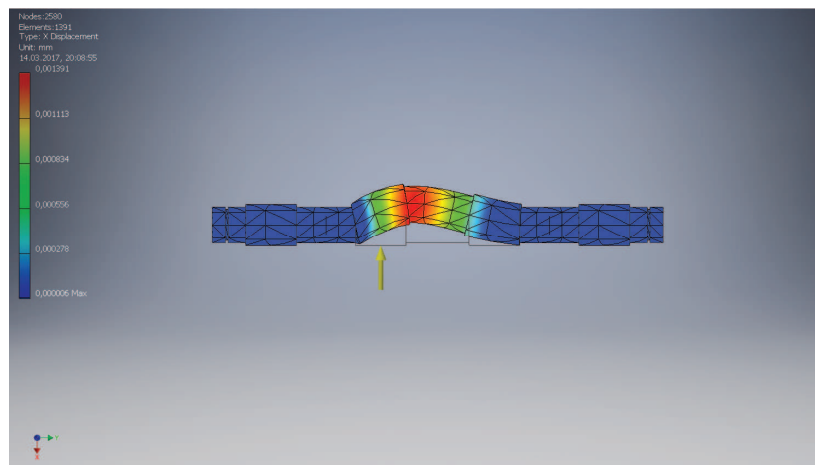

Fig. 22. The displacements of points the sub-model of the rocker arm axis loaded by the force $\mathrm{F}=1000 \mathrm{~N}$ for the inlet valve 
The resulted values of displacement $d_{\text {valve }}$ of points the valve sub-model loaded by the force $\mathrm{S}=330 \mathrm{~N}$ and gas pressure $p=7 \mathrm{MPa}$ were shown in the Figure 23. The estimated stiffness $\mathrm{k}_{\text {valve }}$ value was equal $1,520,000 \mathrm{~N} / \mathrm{mm}$ for the outlet valve and $150,000 \mathrm{~N} / \mathrm{mm}$ for the inlet one.

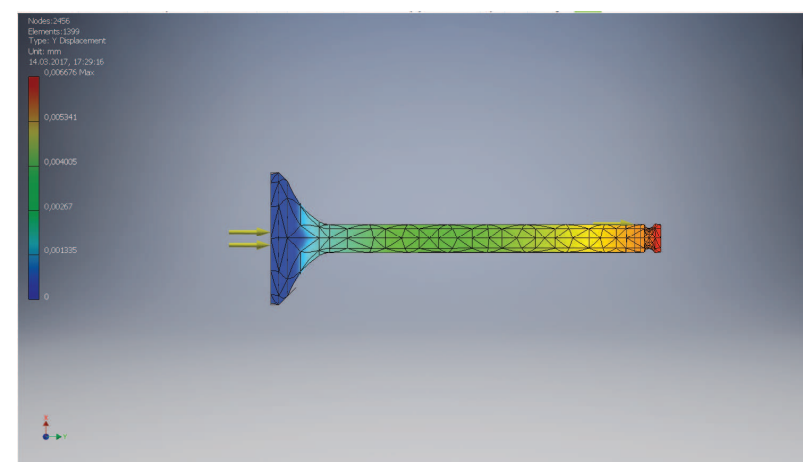

Fig. 23. The displacements of points of the valve sub-model loaded by the force $\mathrm{S}=330 \mathrm{~N}$ and gas pressure $\mathrm{p}=7 \mathrm{MPa}$

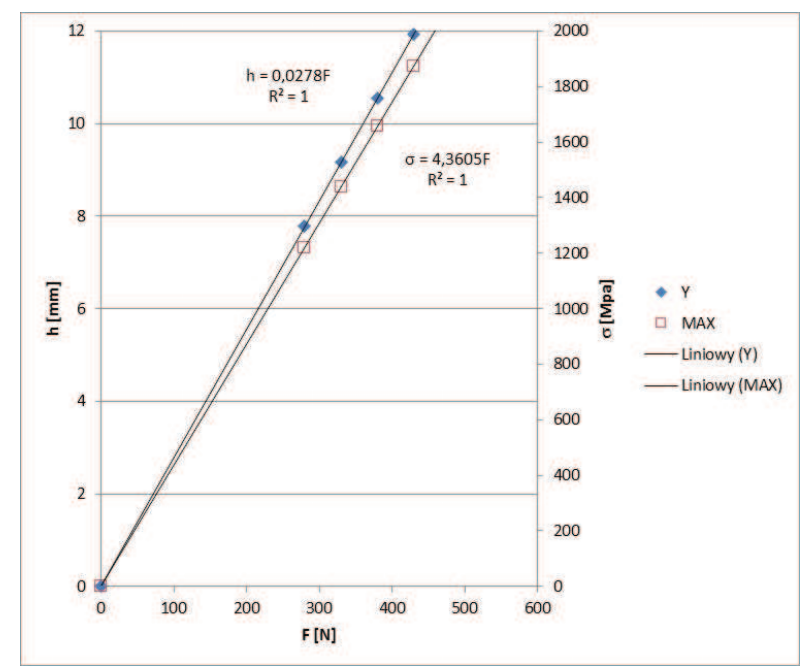

Fig. 24. Displacement and maximum von Misses stress against loading force for the large machined spring

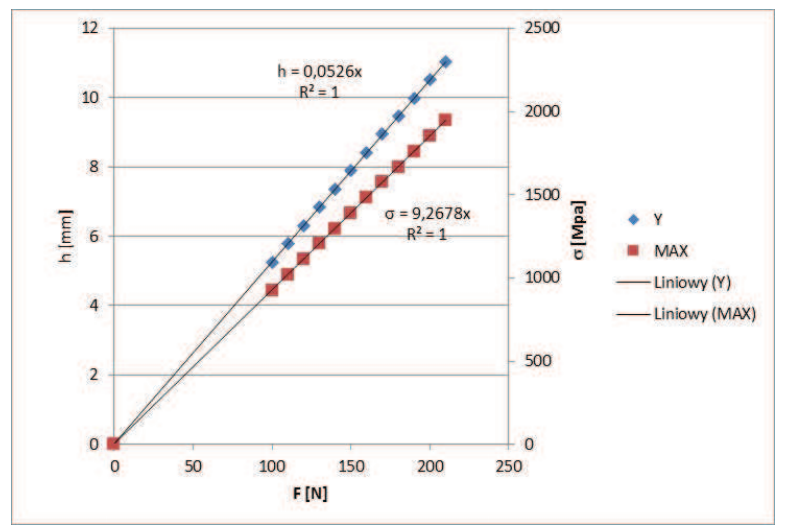

Fig. 25. Displacement and maximum von Misses stress against loading force for the large machined spring

The resulted values of displacements and maximum von Misses stresses as a function of loading force were presented in the Figure 24 - for the large machined spring and in Figure 25 - for the small machined spring. The obtained courses were of the linear nature. The spring rates were equal the inverse of the slope the function $h(F)$. For the large spring its rate was equal $36 \mathrm{~N} / \mathrm{mm}$ and for the small machined spring the rate was of $19 \mathrm{~N} / \mathrm{mm}$. As the springs operate in parallel configuration, so equivalent rate of the spring set was equal $55 \mathrm{~N} / \mathrm{mm}$.

The obtained distributions of displacements for the large machined spring loaded with the force $\mathrm{F}$ were shown in the Figure 26 and in the Figure 27 - for the small one. Maximal displacement in both cases was about $9.5 \mathrm{~mm}$.

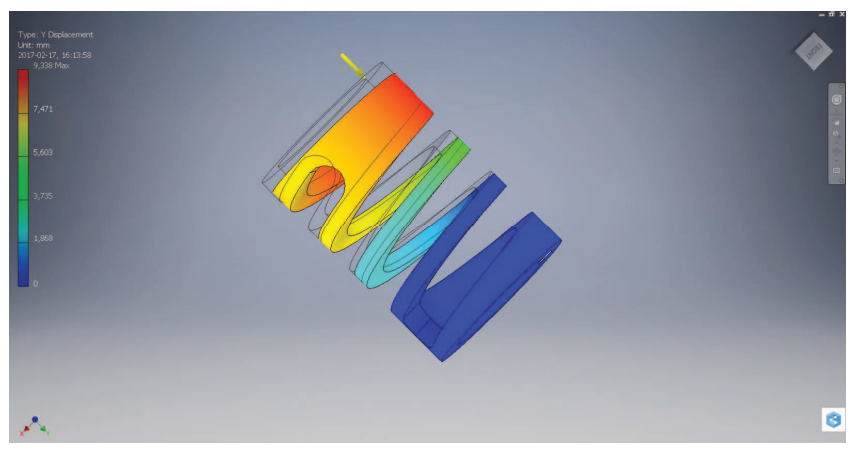

Fig. 26. Distribution of displacements for large machined spring loaded with the force $\mathrm{F}$ equal $430 \mathrm{~N}$

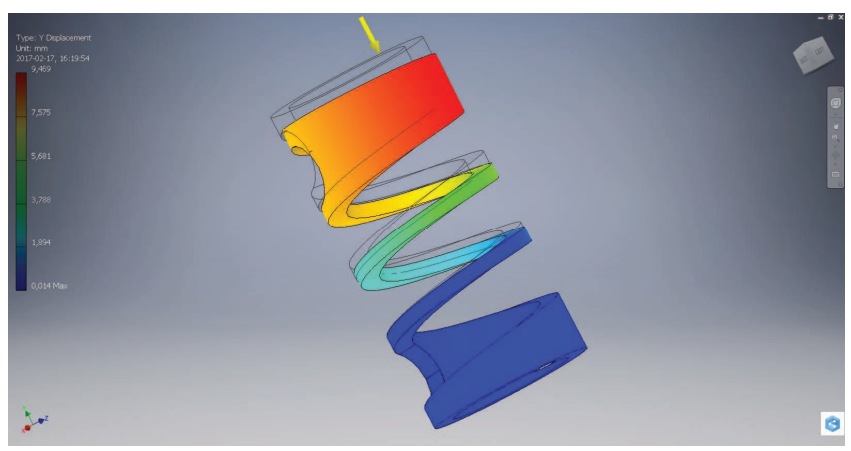

Fig. 27. Distribution of displacements for small machined spring loaded with the force $F$ equal $180 \mathrm{~N}$

The corresponding von Misses stress distributions were shown in the Figure 28 - for large spring and in the Figure 29 - for the small one. The maximum von Misses stresses for the large spring loaded by the force $\mathrm{F}=430 \mathrm{~N}$ was of $1582 \mathrm{MPa}$ and for the small spring loaded by the force $\mathrm{F}=$ $180 \mathrm{~N}$ was of 1,668 MPa. The points of maximal von Misses stresses were located near the inner diameters of springs.

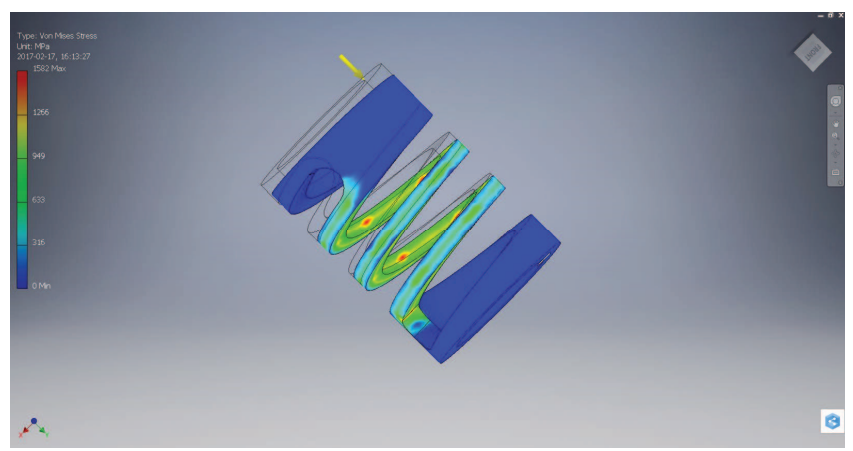

Fig. 28. Distribution of von Misses stresses for large machined spring loaded with the force $\mathrm{F}$ equal $430 \mathrm{~N}$ 
The obtained courses of the inlet valve lift and acceleration against time were presented in the Figure 30 - for the coil valve springs and in the Figure 31 - for the machined springs. The use of machined spring resulted in the twice lower amplitude of small vibrations with the high frequency, probably due higher weight of the machined spring in comparison to the coil one.

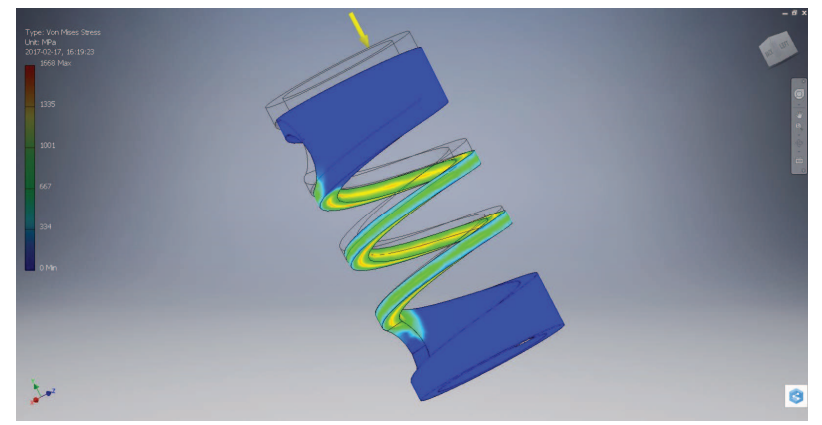

Fig. 29. Distribution of von Misses stresses for small machined spring loaded with the force $\mathrm{F}$ equal $180 \mathrm{~N}$

a)
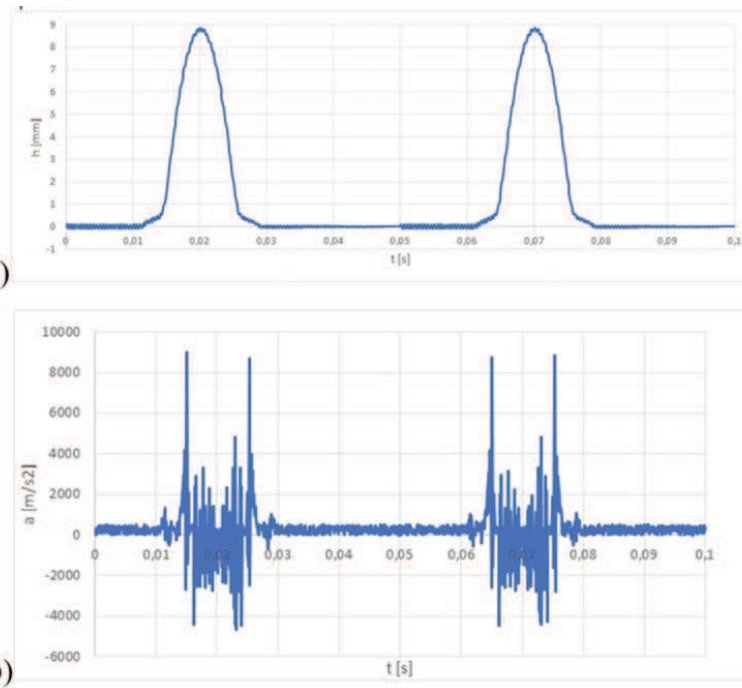

Fig. 30. Courses of the inlet valve a) lift and b) acceleration against time for the coil valve springs

a)
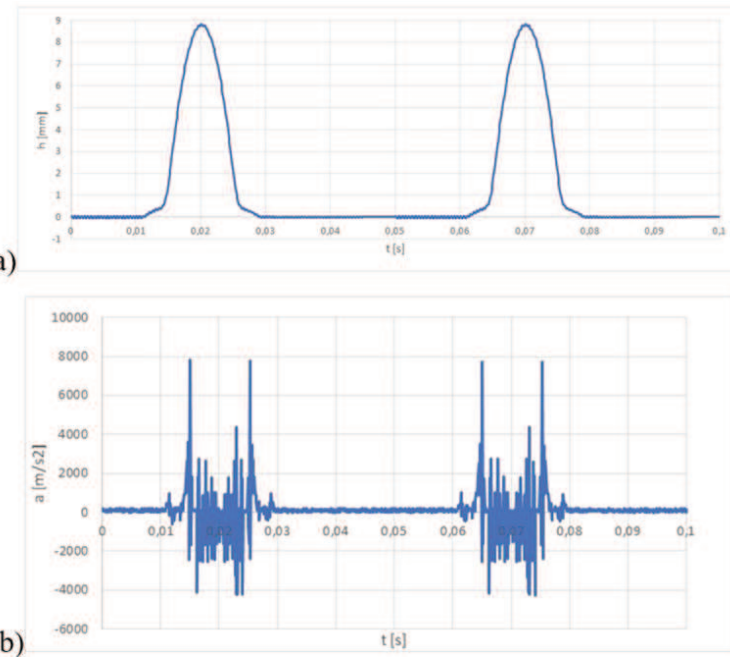

The obtained courses of the outlet valve lift and acceleration against time were presented in the Figure 32 - for the coil valve springs and in the Figure 33 - for the machined springs. The use of machined spring resulted in the twice lower amplitude of small vibrations with the high frequency, probably again due higher weight of machined spring in comparison to the coil one. The occurrence of gas pressure in the beginning of valve opening resulted in the 1.5 times lower amplitude of small vibrations with the high frequency in comparison to the case of the inlet valve.

a)

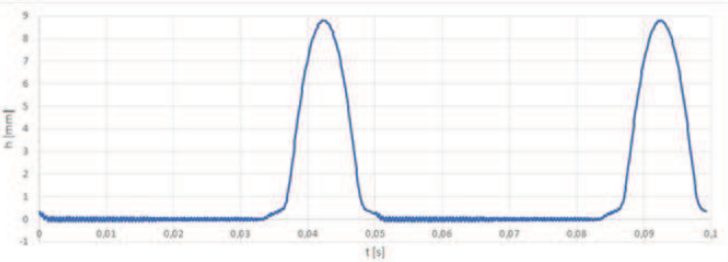

b)

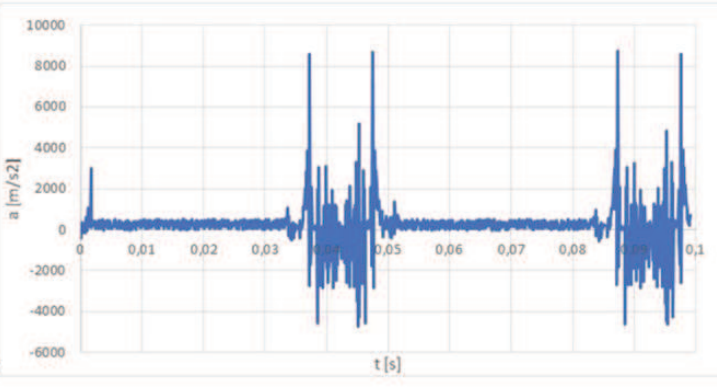

Fig. 32. Courses of the a) lift and b) acceleration of the outlet valve against time for the classical valve springs

Modal frequency values were calculated for the range 0$700 \mathrm{~Hz}$, as current engines can operate with the speed up to 19,000 rpm [49]. The obtained modal frequency values for inner and outer machined springs were shown in the Table 1. For common engines operating with the speed up to $6,000 \mathrm{rpm}$ the existence of spring resonances was hardly to observe.

a)
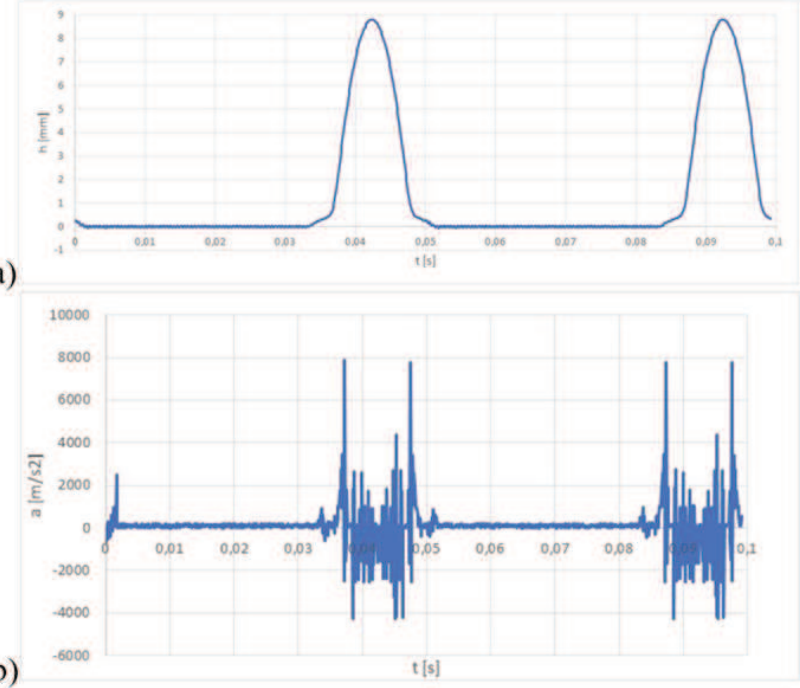

Fig. 33. Courses of the a) lift and b) acceleration of the inlet valve against time for the machined valve springs

Fig. 31. Courses of the a) lift and b) acceleration of the inlet valve against time for the machined valve springs 
Table 1. Modal frequency against number of mode for machined springs

\begin{tabular}{|l|c|c|}
\hline \multirow{2}{*}{ Number of mode } & \multicolumn{2}{|c|}{ Modal frequency [Hz] } \\
\cline { 2 - 3 } & Inner spring & Outer spring \\
\hline 1 & 211.97 & 165.26 \\
\hline 2 & 285.43 & 170.52 \\
\hline 3 & 287.80 & 268.63 \\
\hline 4 & 352.89 & 365.23 \\
\hline 5 & 413.26 & 707.05 \\
\hline 6 & 422.41 & 711.28 \\
\hline 7 & 589.11 & 1031.54 \\
\hline 8 & 619.59 & 1301.54 \\
\hline 9 & 619.58 & 1370.11 \\
\hline 10 & 684.17 & 1710.77 \\
\hline
\end{tabular}
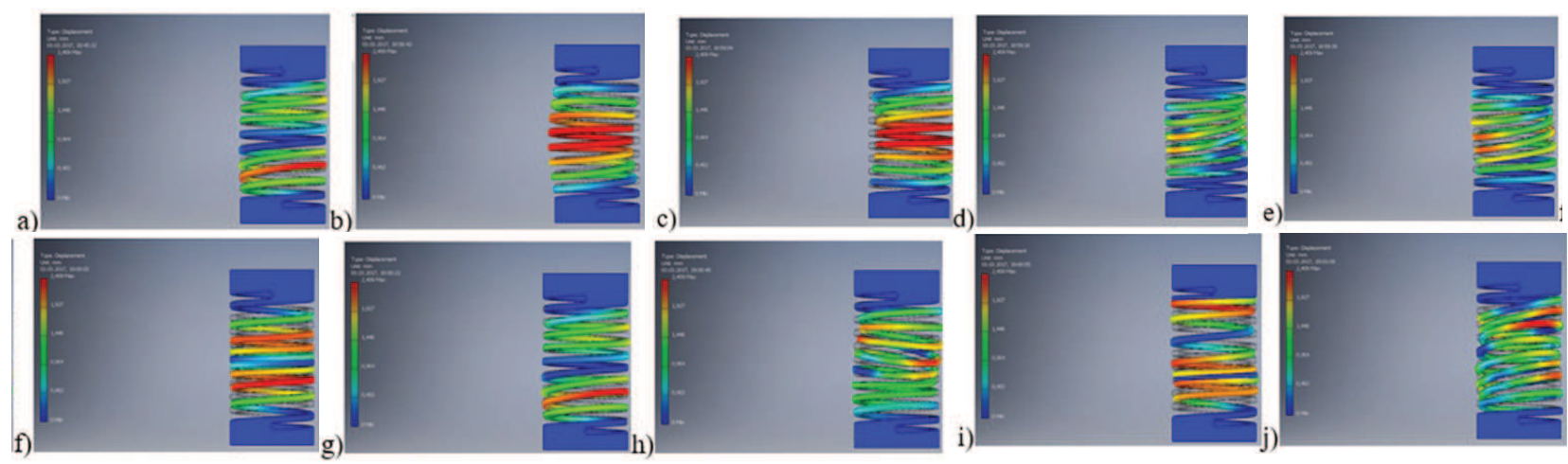

Fig. 34. Modes of the inner machined spring for the different values of modal frequency: a) for the mode number $1, \mathrm{~b}$ ) for the mode number $2, \ldots, \mathrm{j}$ ) for the mode number 10 , respectively

\section{Nomenclature}

FEM finite element method

$\mathrm{CE}$ engine crankshaft rotation angle

OHC over head cam

OHV over head valve
DOHC double over head cam

MA multi-arc

SI spark ignition

CI compressed ignition

\section{Bibliography}

[1] ClenCI, A.C., HARA, V., STANESCU, N-D., BIZILAC, A., NICULESCU, R. Analytical synthesis and computer-aided kinematic analysis of a continuously variable valve lift mechanism. AProc. IMechE Part C: J. Mechanical Engineering Science. 2017, 231(2), 309-325.

[2] JOHANSSON, B. Förbränningsmotorer del 2, 2004.

[3] KRÜGER, K. Einfluss hydraulischer Nockenwellenversteller auf die Dynamik von Ventil- und Steuertrieben, DI Dissertation, Technischen Universität München, 2009.

[4] HEISLER, H. Advanced Engine Technology. SAE International, Warrendale, PA, 1995.

[5] GROHN, M. The new camshaft adjustment system by Mercedes Benz - design and application in 4valve engines. SAE Technical Paper 901727, 1990.

[6] MORIYA, Y., WATANABE, A., UDA, H., KAWAMURA, H., YOSHIOKA, M. A newly developed intelligent variable valve timing system - continuously controlled cam phasing as applied to a new 3 liter inline 6 engine. SAE Technical Paper 960579, 1996.

[7] JÄÄSKELÄINEN, H. Variable valve actuation. 2011, DieselNet. www.dieselnet.com (2012-06-5).

[8] STONE, C.R., KWON, E.K.M. Variable valve timing for IC engines. Automotive Engineer. August/September 1985.
[9] PARKER, P.H. The variable valve timing mechanism for the Rover K16 engine. Part 2: application to the engine and the performance obtained. Proceedings of the Institution of Mechanical Engineers, Part D: Journal of Automobile Engineering. 2000, 214(2), 207-216.

[10] VON JOHANN-GEORG, U., FIEDLER, O., Vo§ H., Motor fur Porsche 968. Motortechnische Zeitschrift 1991, 52(12).

[11] STOFFREGEN, J., Motorradtechnik: Grundlagen und Konzepte von Motor, Antrieb und Fahrwerk Populär. ATZ/MTZ-Fachbuch Springer Vieweg Populär. Kraftfahrzeugtechnik, Springer-Verlag. 2012.

[12] Ventiltrieb: Systeme und Komponenten, Mahle GmbH, Springer-Verlag, 2012.

[13] INOUE, K., NAGAHIRO, K., AJIKI, Y., KISHI, N. A high power, wide torque range, efficient engine with a newly developed variable valve lift and -timing mechanism. SAE Technical Paper 890675, 1989.

[14] LANCEFIELD, T., LAWRENCE, N., AHMED, A., BEN HADI HAMOUDA, H. VLD a flexible, modular, cam operated VVA system giving variable valve lift and duration and controlled secondary valve openings, SIA-IFP (2006).

[15] my.ms-motorservice.com/fileadmin/media/kspg /Broschueren/Produktbroschueren/_Pierburg/Variabler_Ventiltrieb/Bro_Var_Ventiltrieb_EN_web.pdf (available 2017.02.12). 
[16] YAMAGUCHI, J. Super-economy lean-burn engines from Mitsubishi and Honda - techbriefs. Automotive Engineering. 1991, 11(99).

[17] asia.vtec.net/spfeature/vtecimpl/vtec1.html (available 2017.02.12)

[18] paultan.org/2006/03/13/2006-honda-civic-18-sohc-i-vtecengine/gevtec.html (available 2017.02.12).

[19] www.honda.co.jp/tech/auto/engine/20i-vtec/index (available 2017.02.12).

[20] paultan.org/2006/03/13/2006-honda-civic-18-sohc-i-vtecengine (available 2017.02.12).

[21] www.autozine.org/technical_school/engine/vvt_2.htm (available 2017.02.12)

[22] www.mitsubishi-motors.com/corporate/about_us/ technology/performance/e/mivec.html (available 2017.02.12).

[23] paultan.org/2007/04/17/honda-files-advanced-vtec-patent (available 2017.02.12).

[24] outlander.kiev.ua/manual/Outlander_2.4_AT_MT/11C.pdf (available 2017.02.12).

[25] www.datsuncr.com/motores-nissan-datsun.html (available 2017.02.12).

[26] www.neovvl.com/whatisneovvl.php (available 2017. 02.12).

[27] www.sr20-forum.com/vvl/40827-ve-factory-nissan-camspecs.html (available 2017.02.12).

[28] paultan.org/2008/02/06/proton-waja-campro-16-premiumcps-details (available 2017.02.12).

[29] MILOVANOVIC, N., DAVE, B., GEDGE, S., TURNER, J. Cam profile switching (CPS) and phasing strategy vs fully variable valve train (FVVT) strategy for transitions between spark ignition and controlled auto ignition modes. SAE Technical Paper. 2005, 2005-01-0766.

[30] ZHAO, H. HCCI and CAI engines for the automotive industry. Elsevier. 2007.

[31] www.delphi.com/manufacturers/auto/powertrain/ gas/valvetrain/2step (available 2017.02.12).

[32] www.yamaha-motor.eu/designcafe/de/ (available 2017. 02.12).

[33] www.nissan-global.com/EN/TECHNOLOGY/OVERVIEW/ vvel.html (available 2017.02.12).

[34] ThyssenKrupp techforum Juli 2004 (available 2017. 02.12).

Krystian Siczek - Faculty of Electrical, Electronic, Computer and Control Engineering at Lodz University of Technology.

e-mail: Krystian.Siczek@p.lodz.pl
[35] DABROWSKI, A., GLOGOWSKI, M., KUBIAK, P. Improving the efficiency of four-stroke engine with use of the pneumatic energy accumulator - simulations and examinations. International Journal of Automotive Technology. 2016, 17(4), 581-590).

[36] BALL, A.D., DOWSON, D., et al. Cam and follower design. In: Tribology Series. 1988, 14, 111-130.

[37] NUNNEY, M.J. Light and heavy vehicle technology. Elsevier, 2013, 514.

[38] HUBER, R. Dynamics of variable valve trains and extrapolation methods for time-stepping schemes. PhD Thesis, Technischen Universität München, 2012.

[39] VAN BASSHUYSEN, R., SCHAFER, F. Internal combustion engine handbook: basics, components, systems, and perspectives. SAE International, 2004.

[40] MUHR, T.H. New technologies for engine valve springs. SAE Technical Paper. 1993, 930912.

[41] HILLIER, V. Hillier's fundamentals of motor vehicle technology. Nelson Thornes, 6 edition, 2004.

[42] SEMET, W. Entwicklung einer pneumatischen Ventilfeder für hochdrehende Serienmotoren, $\mathrm{PhD}$ thesis, Universität Stuttgart, 2007.

[43] Pick-a-Part: Selecting valvetrain components for a performance build. Engine Builder, February 2014.

[44] SUDHAKAR, K.V., Failure analysis of an automobile valve spring. Engineering Failure Analysis. 2001, 8(6), 513-520.

[45] YU, Z-W., XU, X-L. Failure analysis on diesel-engine valve springs. Journal of Failure Analysis and Prevention. 2009, 9(4), 329-334.

[46] PATEL SUJAL, V., PAWAR SHRIKANT, G. Failure analysis of exhaust valve spring of C.I. engine. International Journal of Engineering Research \& Technology (IJERT). 2013, 2(3).

[47] BOEHM, G.L. Wire springs versus machined springs. A comparison, $P E$ - 15 SEP 14 - Version 16, Helical Products Co. MW Industries, Inc. Santa Maria, USA.

[48] Machine spring displacer for Stirling cycle machines, Patent US7017344 B2.

[49] www.f1network.net/main/s107/st66401.htm (available 2017. 02.12).

Krzysztof Siczek, DSc., DEng. - Faculty of Mechanical Engineering at Lodz University of Technology.

e-mail: ks670907@p.lodz.pl
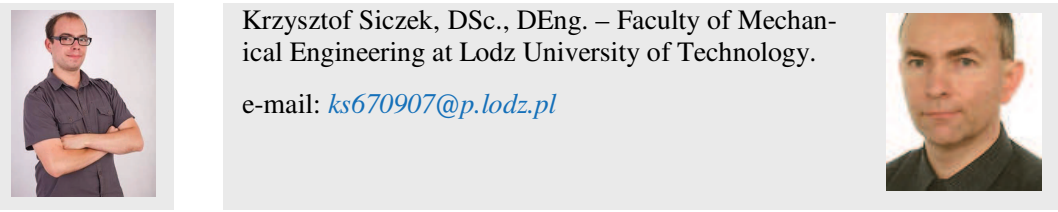